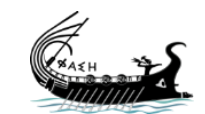

journal.phaselis.org

\title{
Antik Kaynaklar Işığında Megalesia Festivali
}

\author{
Megalesia Festival in the Scope of Ancient Sources
}

\section{Asuman COŞKUN ABUAGLA}

open 2 access journals

The entire contents of this journal, Phaselis: Journal of Interdisciplinary Mediterranean Studies, is open to users and it is an 'open access' journal. Users are able to read the full texts, to download, to copy, print and distribute without obtaining the permission of the editor and author(s). However, all references to the articles published in the e-journal Phaselis are to indicate through reference the source of the citation from this journal.

Phaselis: Journal of Interdisciplinary Mediterranean Studies is a peer-reviewed journal and the articles which have had their peer reviewing process completed will be published on the web-site (journal.phaselis.org) in the year of the journal's issue (e.g. Issue II: January-December 2016). At the end of December 2016 the year's issue is completed and Issue III: January-December 2017 will begin.

Responsibility for the articles published in this journal remains with the authors.

Citation A. Coşkun-Abuagla, "Antik Kaynaklar Işığında Megalesia Festivali". Phaselis III (2017) 271-280. http://dx.doi.org/10.18367/Pha.17016

Received Date: 15.10.2017 | Acceptance Date: 04.12.2017 | Online Publication Date: 20.12.2017

Editing Phaselis Research Project

www.phaselis.org 


\title{
Antik Kaynaklar Işığında Megalesia Festivali
}

\author{
Megalesia Festival in the Scope of Ancient Sources
}

\author{
Asuman COŞKUN ABUAGLA*
}

Öz: Tanrıça Kybele, antik Hellen ve Roma dünyasında en önemli tanrıçalardan biridir. Bu tanrıçanın MÖ ı. bin yıldan MS V. yüzyıla kadar uzanan tapımı ilk olarak Phrygia'da ortaya çıkmış, şekillenmiş ve buradan antik Hellen ve Roma dünyasına yayılmıştır. MÖ VII. yüzyıla tarihlenen yazıtlarda Frigce "Matar" (Ana), MS

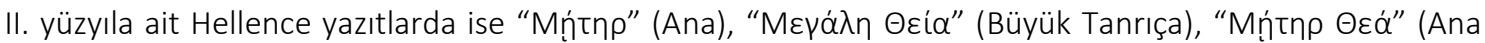
Tanrıça) ve "Mṇ́tn $\theta \varepsilon \tilde{\omega} v^{\prime}$ (Tanrıların Anası) olarak adlandırılan tanrıçanın, antik Hellen tapımında saygın yere sahip olduğu anlaşılmaktadır. Antik Roma'da "Magna Mater" (Büyük Ana) ve "Mater Deum Magna Idaea" (Tanrıların Idalı Büyük Anası) lakaplarıyla bilinen Kybele, MÖ III. yüzyılda Roma Devleti'nin kurtarıcısı olması için Phrygia'dan Roma'ya getirilmiş ve Palatium Tepesi'ne yerleştirilmiştir. Bu tarihten itibaren tanrıça Kybele'nin onuruna 4-10 Nisan tarihleri arasında ilginç törenlerin yapıldığı ve görkemli sahne oyunlarının düzenlendiği Megalesia Festivali kutlanmış ve böylece tanrıça, devletin kurtarıcısı ve koruyucusu olarak antik Roma'da en seçkin yeri kazanmıştır. Bu makalenin amacı antik kaynaklar ışığında, tanrıça Kybele onuruna Roma'da kutlanan Megalesia Festivali hakkında genel bir bilgi vermekti.

Anahtar sözcükler: Phrygia, Kybele, Tanrıların Anası, Antik Roma, Kurtarıcı

Abstract: Cybele is the most important goddess in the ancient Greek and Roman world. Her cult extending from the $I^{\text {st }}$ millenium $B C$ to the $V^{\text {th }} A D$ was first accepted and formed in Phrygia in Anatolia and hence spread to the ancient Greek and Roman world. The goddess called "Matar" (Mother) in Phrygian language in the inscriptions dated $\mathrm{VII}^{\text {th }}$ century BC was named in ancient Greek inscriptions dated II $^{\text {nd }}$

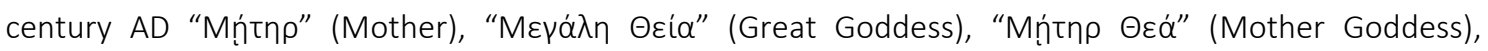
"Mṇ́tnp $\theta \varepsilon \tilde{\omega} v$ " (Mother of the Gods) and so she gained one of the most distinguished place in the cult of ancient Greece. The goddess was brought to Rome from Phrygia in 204 BC so that she might be the saviour of the state of Rome and placed on the Palatine Hill. Since then for the goddess, called Magna Mater" (Great Mother) and "Mater Deum Magna Idaea" (Great Idaean Mother of the Gods) in the ancient Roman world, in the month of April a festival called Megalesia in which extraordinary ceremonies and magnificent theatre plays had been arranged, was celebrated. In this article in the light of ancient sources, I aim to give general information about the Megalesian Festival celebrated in honour of the goddess Cybele.

Keywords: Phrygia, Cybele, Goddess of the Gods, Ancient Rome, Savior

Ops, Rhea, Magna Mater, Mater Deum Magna Idaea, Dindymene, Cybebe Mater adlarıyla da bilinen tanrıça Kybele'nin kutsal ayinlerinin, Roma'ya yayılmadan önce, Phrygia'daki Ida Dağı'nda yapıldığı söylenir ${ }^{1}$. II. Kartaca Savaşı'nın Roma halkı üzerinde yarattığı sıkıntı, ruhsal bunalım ve halkın, batıl inançlara gösterdiği geleneksel tutkunluk, üstüne üstlük MÖ 205/204 yılında

* Yrd. Doç. Dr., Akdeniz Üniversitesi, Eskiçağ Dilleri ve Kültürleri Bölümü, Latin Dili ve Edebiyatı, Antalya. asumancoskun@akdeniz.edu.tr

1 Mṇin $\theta \varepsilon \tilde{\omega} v$ için bk. Coşkun-Abuagla 2013, 132-134. 
gökyüzünden zaman zaman taş yağması, Romalıları, adını Euboea kolonisi Cumae'da yaşamış kâhine Sibylla'dan alan Sibylla kitaplarına danışmak zorunda bırakır. Livius, kutsal Sibylla kitaplarının, Magna Mater Roma'ya getirilirse, yabancı bir düşmanın (= Hannibal) italya'dan çıkartılacağını bildirdiğini nakleder². Bu bağlamda kitaplardan alınan yanıın, halkın ruh haline göre şekillendirilmiş olduğu da düşünülebilir.

Daha sonra mali kaynaklarıyla güçlü Roma artık beş yüzyılı devirdiğinde ve alt ettiği dünyadan başını kaldırdı̆̆ında, bir rahip inceler Euboialı kehanetin yazgısal sözlerini; söylerler incelemenin şöyle sonuç verdiğini:

'Ana uzaktadır: Buyuruyorum, ey Romalı, anayı aramanı. Geldiğinde, kabul edilmelidir temiz bir elle.' Senatörler anlaşılmaz kehanetin belirsizliğinden tereddüt ederler, hem uzakta olan ana kimdir hem de nerede aranmalıdır diye ${ }^{3}$.

(Ovid. Fasti IV. 255-262)

Tanrıçanın nerede aranması gerektiği hakkında bazı rivayetler vardır. Bu konuda antik kaynakların çoğu, Magna Mater'in, Phrygia'daki kutsal yeri Pessinus'tan getirildiğini söyler ${ }^{4}$. Varro, tanrıçanın Pergamon kentindeki Megalesion Tapınağı'ndan ${ }^{5}$, Ovidius ise onun, Troya kenti yakınındaki Ida Dağı'ndan getirildiğini nakleder. Ovidius'un bu ifadesi, Ana tanrıça'yı Troya dağlarıyla, dağları da Roma'nın efsanevi geçmişiyle bağlamaya çalışmasından kaynaklanmış olmalıdır.

"Dindymus'u, Cybele'yi ve pınarlarıla şirin Ida'yı ve daima sevdi Ana Tanrıça Troia krallığını". (Ovid. Fasti IV. 249-250).

Ovidius'a göre, Sibylla kitaplarından alınan yanıtın ne anlama geldiği anlaşılmayınca, senatörler, Apollo kehanetine danışmak üzere Marcus Valerius Laevinus'u, Marcus Caecilius Metellus'u, Sulpicius Galba'yı, Gnaeus Tremellius Flaccus'u ve Marcus Valerius Falto'yu, elçiler olarak Roma'dan Delphoi'a gönderirler ve tanrıdan şöyle bir yanıt alırlar:

Paean'a danışılır, 'tanrıların Anası'nı alıp getirin, Ida'nın doruğunda bulunmalıdır' dedi'. (Ovid. Fasti IV. 263-264).

Böylece Roma Senatus'u, Roma'dan Phrygia'ya elçiler gönderir ancak Ovidius'un anlatımından o sırada bölgeye hükmeden kral I. Attalus'un, Romalı elçilerin isteklerine karşı çıktığı anlaşımaktadır.

2 Liv. XXIX.10: ciuitatem eo tempore repens religio inuaserat inuento carmine in libris Sibyllinis propter crebrius eo anno de caelo lapidatum inspectis, quandoque hostis alienigena terrae Italiae bellum intulisset eum pelli Italia uincique posse si mater Idaea a Pessinunte Romam aduecta foret.

3 Coşkun-Abuagla 2016, 186.

4 Cic. DHR. 13. 28: Pessinuntem ipsum, sedem domiciliumque Matris deorum, etc. Liv. XXIX. 10: mater Idaea a Pessinunte Romam aduecta, etc.

Amm. Marc. 22. 9, 5-7: Pessinunta convertit, visurus vetusta Matris magnae delubra, a quo oppido bello Punico secundo, carmine Cumano monente per Scipionem Nasicam simulacrum translatum est Romam.

Arnob. AN., 7. 49: "Sed et Magna, inquit, Mater accita ea Phrygio Pessinunte iussis consimiliter vatum salutaris populo et magnarum causa laetitiarum fuit, etc". Ayrıca bk. Roller, 1999, 255.

5 Varro Ling. VI. 15: quod ex Libris Sibyllinis arcessita ab Attalo rege Pergama; ibi prope murum Megalesion, id est templum eius deae, unde advecta Romam. Ayrıca bk. Roller 1999, 255.

6 Coşkun-Abuagla 2016, 186.

7 Coşkun-Abuagla 2016, 186. 
Bunun üzerine tanrıça, tapınağının kutsal yerinden dile gelip, bizzat kendisinin Roma’ya gitmek istediğini söyler.

\section{Gönderilir soylu adamlar. Phrygia'da hükümdarlık asasını tutuyordu o zaman Attalus: Bu Ausonialı adamlara izin vermez. Hayret verici şeyler terennüm edeceğim: Sarsıldı toprak uzun bir uğultuyla ve tapınağının kutsal odasından şöyle konuştu tanrıça: \\ "Alınmayı bizzat ben istedim, geciktirme ve gönder gitmek isteyen beni. Roma uygun bir yerdir her tanrının gitmesi için". Beriki sesten duyduğu korkudan dehşete kapılıp 'yola çık' dedi, 'yine de olacaksın sen bizim: Roma, Phrygialı atalarının izini sürecektir'.}

(Ovid. Fasti IV. 265-274).

Ovidius'un anlatımından Pessinus'tan Roma'ya getirilen şeyin Magna Mater'in yontusu olduğu sanılabilir, ama antik yazarların birçoğu, Romalıların Pessinus'tan ne getirdiklerini tam olarak açıklamışlardır. Buna göre, Phrygia'daki Pessinus Dağı'na gökten düşen ve Phrygialıların tanrıların anası olarak taptıkları küçük, kara bir taş, MÖ 204 yılında Roma'ya getirilmiştir ${ }^{9}$. Kutsal Sibylla kitapları, tanrıçanın Roma'da nasıl karşılanması gerektiğini önceden bildirmişlerdi. Buna göre kentin en iyi adamının (vir optimus), tanrıçayı karşılaması gerekmekteydi. Bunun için İspanya'da öldürülen Romalı asil yurttaşlardan biri olan Gnaeus Scipio'nun oğlu Publius Cornelius Scipio Nasica seçilir. Corculus olarak da adlandırılan Nasica, iki kere consul ve censor olarak seçilmiş mükemmel bir hatiptir ${ }^{10}$. Magna Mater, ayrıca Roma'nın ileri gelen kadınlarından oluşan bir grup ya da kentin en iffetli kadını tarafından karşılanarak kente götürülmeliydi. Antik yazarlar bu kişinin evli bir kadın olan Claudia Quinta olduğunu söylerler ${ }^{11}$. Ovidius ise onun bakire bir kız (virgo) olduğu konusunda ısrar eder ve bu iddiasını hem Magna Mater'in kente girişinde yaşanan mucizevî olaya hem de Aventinum Tepesi'ndeki Bona Dea Tapınağı'na ilişkin dizeleriyle kanitlar ${ }^{12}$.

Tanrıçanın naklini sağlamak için elçi olarak yollanan Marcus Valerius Falto, Magna Mater'i getiren geminin Ostia'ya vardığını Senatus'ta duyurduğunda, Scipio Nasica önderliğindeki halk, tanrıçayı karşılamak için Ostia Limanı'na akın eder. Bu noktada Livius, Scipio'nun gemiye çıkarak kara taşı aldığını sonra onu, aralarında Claudia Quinta'nın da bulunduğu Roma'nın ileri gelen

\section{Coşkun-Abuagla 2016, 187.}

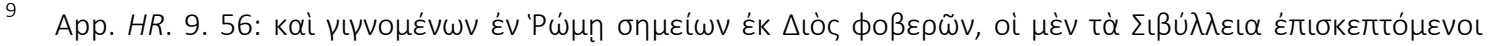

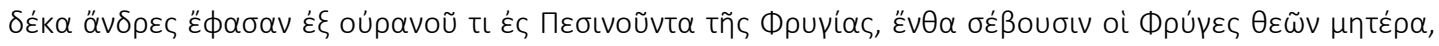

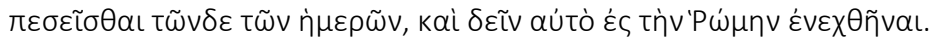

Arnob. AN., 7. 49: ex Phrygia nihil quid aliud scribitur missum rege ab Attalo, nisi lapis quidam non magnus, ferri manu hominis sine ulla inpressione qui posset, coloris furvi atque atri, angellis prominentibus inaequalis, etc. Ayrica bk. Roller 1999, 255.

10 Cic. Brut. 20. 79: P(ublium) etiam Scipionem Nasicam, qui est Corculum appellatus, qui item bis consul et censor fuit, habitum eloquentem aiunt, etc.

Liv. XXIX. 14: P(ublium) Scipionem Cn(aii) filium eius qui in Hispania ceciderat, adulescentem nondum quaestorium, iudicauerunt in tota ciuitate uirum bonorum optimum esse, etc.

Plin. nat., VII. XXXIV. 120: Vir optimus semel a condito aevo iudicatus est Scipio Nasica ab iurato senatu, etc.; Ayrica bk. Roller 1999, 255-256.

11 Liv. XXIX.14: inter quas unius Claudiae Quintae insigne est nomen, etc.

Plin. nat. VII. XXXIV. 120: Pudicissima femina semel matronarum sententia iudicata est, etc./ iterum religionis experimento Claudia inducta Romam deum matre.

12 Coşkun-Abuagla 2016, 232 (Ovid. Fasti V. 155-158): “Adar bunu Clausus Sülalesi'nin eski adını taşıyan varisesi, | bakire bedenine hiçbir erkeğin değmediği". 
kadınlarına verdiğini, kadınların da bunu Palatium Tepesi'ndeki Zafer Tapınağı'na (Templum Victoriae) götürdüklerini nakleder ${ }^{13}$. Ovidius ise bu kara taşın bir gemiyle Roma'ya nasıl getirildiğini anlatırken geminin Tiber Nehri'nden kıyıya çekildiği sırada karaya oturduğunu, bir türlü yerinden oynatılamadığını söyler ve bu noktada Claudia Quinta'ya ilişkin söylentiyi ele alır. Attus Clausus, bir Sabin kasabası olan Regillum'dan Roma'ya göç etmiştir ve Roma'nın son kralı Tarquinius Superbus'un kovulmasından beş yıl sonra Attus Clausus'un ailesi, soylular arasına kabul edilerek Attus, Appius Claudius olarak adlandırılmıştır. Ovidius'un Claudia Quinta olarak bahsettiği genç kız, işte bu Appius Claudius Caecus'un büyük torunudur. Ovidius'un anlatımına göre, Claudia Quinta genç bir kız olarak zamanının geleneklerine uygun davranmadığı için adına sürülen lekeleyi temizlemek ve bakire olduğunu kanıtlamak için önce nehrin suyuyla ellerini ıslatır, başını üç kez mesheder ve ellerini üç kez gökyüzüne kaldırıp, Ana tanrıça'ya yakarır. Belindeki kemerini çözer ve onu, gemiyi çeken halata bağlar, sonra halata hafifçe asılıp, gemiyi yerinden oynatarak Roma'ya kadar çeker. Böylece Sibylla kitaplarında işaret edilen temiz ellerin (casta manus) sahibinin Claudia Quinta olduğu kanıtlanır.

Gemi oturur tıpkı denizin ortasında sabit bir ada gibi mucizeyle çarpılan adamlar hem ayakta dururlar hem de sarsılırlar. Claudia Quinta alıyordu soyunu soylu Clausus'tan, aşağı kalır değildi yüzü de soyluluğundan.

Temizdi gerçekten, heyhat temiz olduğuna inanılmayan:

Yersiz bir söylentiyle lekelenmiş ve iftiraya kurban gitmişti; giyim şekli ve süslü püslü yaptırdığı saçlarıyla ortalıkta görünmesi zarar verdi ona ve hazırcevaplığı sert yaşlılara. Erdeminden emin, söylentinin yalanlarına gülüp geçti, ne var ki kötü söylentilere hemen inanan bir güruhuz biz.

$B u$, temiz anaların alayından çıkı da nehrin temiz suyunu elleriyle aldıktan sonra, üç kez başını ıslatır, üç kez semaya kaldırır ellerini (onu görenler, aklını yitirdiğini sanırlar) dizini büküp bakışlarını tanrıçanın yontusuna diker ve dağınık saçlarıyla şu sözleri söyler: "Ey sevecen tanrıça, tanrıların bereketli anası, yalvarıcının dualarını kabul eyle, kesin bir şarta bağı olarak.

Temiz olmadığım söyleniyor. Eğer suçlu olduğuma hükmedersen, bunu hak ettiğimi itiraf edeceğim; tanrıçanın hükmüyle mahkûm edilirsem, cezamı ölümle ödeyeceğim, ama eğer suçsuzsam, sen hayatım için bir şeyle güvence vereceksin ve ey temiz tanrıça, temiz ellerimi takip edeceksin". Böyle söyledi ve az bir çabayla halatı çekti (hayret verici olsa da anlattı̆̆ım şey, kanıtlanmıştır sahnede de): Hareket eder tanrıça ve kılavuzunu takip eder, takip etmekle onun temiz olduğunu onaylar, sevincin belirtisi bir çığlık atılır yıldızlara doğrư ${ }^{14}$. (Ovid. Fasti IV. 303-328). 
Ovidius'a göre Publius Cornelius Scipio Nasica, tanrıçayı simgeleyen kara taşı, önce Capitolium'a sonra Palatium Tepesi'ndeki Zafer Tapınağı'na yerleştirir. Livius, kara taşın Zafer Tapınağı'na taşındığı gün, festival kutlamalarına başlandığını, tanrıçanın gelişi şerefine lectisternium ${ }^{15}$ ve Megalesia olarak adlandırılan oyunlar (ludi Megalesia) düzenlendiğini, Roma halkının tanrıçaya hediyeler sunduğunu söyler ${ }^{16}$. Varro, Megalesia sözcüğünün Hellence'den geldiğini, tanrıçanın Pergamum'daki Megalesion adlı tapınağından ötürü festivalin böyle adlandırıldığını yazar ${ }^{17}$.

Magna Mater'in Roma'ya geldiği gün Kybele tapımı, Anadolu dağlarından Roma dünyasına yayılmış olur. MÖ 204 yılında Metellus Livius'la Gaius Claudius'un censor'luğunda, Marcus Cornelius'la Publius Sempronius'un consul'lüklerinde Senatus kararıyla tanrıça için Palatium Tepesi'nde yaptırılmasına karar verilen tapınak, on üç sene sonra Marcus lunius Brutus tarafından tamamlanarak hizmete açılır (MÖ 191). Livius, tapınağın hizmete açıldığı gün, Roma yıllıkçısı Antias Valerius tarafından Megalesia olarak adlandırılan tiyatro oyunlarının (Megalesia ludi scaenici) ilk kez sahnelendiğinin kaydedildiğini aktarırken ${ }^{18}$, kendisi bu oyunların ilk kez MÖ 195 yılında, Aulus Atilius Serranus'la Lucius Scribonius Libo'nun aedilis'liklerinde sahnelendiğini vurgular $^{19}$. Ancak Livius, festivalin ilk kez kutlanmaya başladığı tarihleri eserinin iki yerinde farklı verdiği için (Liv. XXXIV. 54 ve XXXVI. 36) kendi içinde tutarsızlık gösterir ${ }^{20}$. Tüm veriler ele alındığında festivalin Ana Tanrıça'nın Roma kentine girdiği MÖ 204 yılından itibaren kutlanmaya başladığı ama Megalesia tiyatro gösterilerinin festival programına sonraki yıllar eklendiği anlaşılır. Tanrıçanın Palatium Tepesi'ndeki tapınağı MÖ 111 yılında yangın yüzünden yıkılınca MÖ 101 yılında Gaius Metellus Caprarius tarafından yeniden inşa ettirilir. MS 3 yılında ise Augustus tarafından yeniden elden geçirilir.

Roma geleneklerine göre her sene 4-10 Nisan tarihleri arasında tanrıçanın onuruna düzenlenen ve toga praetexta kuşanan devlet görevlilerinin katıldığı festivalde kurban törenleri praetor'ların başkanlığında yapılırdı ${ }^{21}$. Festival günleri takvimde N (Nefastus) harfiyle belirtilmişti, bu da o günlerde herhangi bir kamu görevinin yapılmasının yasak ve resmî tatil olduğu anlamına gelmekteydi. 4 Nisan'da kentin ileri gelenleri usule uygun şekilde ilân edilen (indicta) ziyafetler

15 Arnob. AN. VII. 32, 8: Habent enim dii lectos atque ut stratis possint mollioribus incubare, pulvinorum tollitur atque excitatur inpressio.

Liv. XXIX. 14: in aedem Victoriae quae est in Palatio pertulere deam pridie idus Apriles; isque dies festus fuit. populus frequens dona deae in Palatium tulit, lectisterniumque et ludi fuere, Megalesia appellata. Ayrıca bk. Roller 1999, 255.

Fest. DSV. XI, “Megalesia ludos" 125: Megalesia ludos Matris Magnae appellabant.

17 Varro Ling. VI. 15: Megalesia dicta a Graecis, quod ex Libris Sibyllinis arcessita ab Attalo rege Pergama; ibi prope murum Megalesion, id est templum eius deae, unde advecta Romam.

18 Liv. XXXVI. 36: locauerant aedem faciendam ex senatus consulto M(etellus) Liuius (et) C(aius) Claudius censores, M(arco) Cornelio (et) P(ublio) Sempronio consulibus; tredecim annis postquam locata erat, dedicauit eam M(arcus) Iunius Brutus, ludique ob dedicationem eius facti, quos primos scenicos fuisse Antias Ualerius est auctor, Megalesia appellatos.

19 Liv. XXXIV. 54: Megalesia ludos scaenicos A(ulus) Atilius Serranus (et) L(ucius) Scribonius Libo aediles curules primi fecerunt.

20 Liv. XXXIV. 54: Megalesia ludos scaenicos A(ulus) Atilius Serranus (et) L(ucius) Scribonius Libo aediles curules primi fecerunt.; ibid., XXXVI. 36: locauerant aedem faciendam ex senatus consulto M(etellus) Liuius (et) $C$ (aius) Claudius censores, M(arco) Cornelio (et) P(ublio) Sempronio consulibus; tredecim annis postquam locata erat, dedicauit eam M(arcus) lunius Brutus, ludique ob dedicationem eius facti, quos primos scenicos fuisse Antias Ualerius est auctor, Megalesia appellatos].

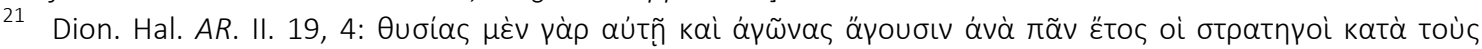

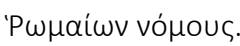


verirlerdi (mutitationes cenarum). Tanıdıklar bu ziyafetlere davet edilmeden katılırlar ve sonra kendileri de karşıık olarak ziyafet verirlerdi. Mutitare (karşılıklı verip almak) denilen bu geleneğin sözcük kökeni, Ovidius'a göre tanrıçanın meskenini değiştirmesinden dolayı mutare (değiştirmek) fiilinden gelmektedir.

"Neden insanlar o zamanlar sık sık karşılıklı ziyafetler verirlerdi ve usulünce ilan edilen ziyafetler kutlarlardı?" diye sordum.

'Çünkü Berecyntia meskenini güzelce değiştirdi' dedi 'onlar da mesken değiştirmekle aynı şansı elde ederler ${ }^{221}$

(Ovid. Fasti IV. 353-356).

Megalesia Festivali'nde tanrıçanın hadım edilmiş rahipleri lotus'tan yapılma kavallarını çalarak ve teflere vurarak tanrıçanın tören alayını sevkederler. Bu oldukça gürültülü bir tören alayıdır, Ovidius buna ilişkin öyküyü Curet'lere ve Corybant'lara dayandırır. Hyginus'un anlattığı söylenceye göre Ida Dağı'nda yaşayan Curet'ler, Ops'un (Rhea) maiyetindeki Phrygialı tanrısal güçlerdi. Ops, Saturnus'tan lupiter'i doğurduktan sonra, luno, Ops'tan onu kendisine vermesini istedi. Saturnus, doğan çocuğun onu krallığından yoksun bırakacağını bildiği için Ops'a ne doğurduğunu sordu. O da sarıp sarmaladığı bir taşı gösterdi, Saturnus o taşı yuttu; ama ne yuttuğunu anlayınca, lupiter'i yeryüzünde aramaya başladı. luno, lupiter'i Girit Adası'na götürdü. Bebeğin dadısı olan Amalthaea, babası onu hiçbir yerde bulamasın diye bebeği bir beşiğin içine koyup, ağaca astı; ağlaması duyulmasın diye de gençleri yanına çağırdı. Onlara küçük bronz kalkanlarla mızraklar verdi ve ağacın etrafında dolaşarak gürültü yapmalarını istedi. Hyginus'un tarifine göre kalkan taşıyanlar Hellence Korybantes, mızrak taşıyanlar ise Kuretes olarak adlandırılmışlardır ${ }^{23}$. Söylenceye göre yedi kardeş olan Corybant'lar nehir tanrısı Asopus'un kızı Combe ile tanrı Socus'un (=Saocus) oğullarıydılar. Kaynaklar onların adlarının Prymneus, Mimas, Acmon, Damneus, Ocythous, Idaius ve Melisseus olduğunu aktarırlar ${ }^{24}$.

"Açıklayın, size verilen buyruğun hatrına, ey Helicon'un evlatları, neden Büyük Tanrıça'nın sürekli sesten zevk aldığını".

Böyle sordum ben. Şöyle yanıt verdi Erato (Venus'un ayı ona boyun eğdi, sahip olduğu için narin aşkın adına):

"Şu kehanet Saturnus'a nakledildi: 'Ey kralların en iyisi, oğlun tarafından krallığından defedileceksin'. Kehanetten korktuğu için o, doğduğu anda her biri yutar kendi zürriyetini ve bağırsaklarında tutar yutuverdiklerini. Yakınıp durdu Rhea sık sık, o kadar doğurgan olup da asla ana olamayan ve karalar bağladı doğurganlığı yüzünden. lupiter doğmuştu (eski kehanetin gerçekleştiğine inanılır büyük tanıktan dolayı; sarsmaktan kaçın kabul gören inancı!):

22 Coşkun-Abuagla 2016, 191.

23 Hyg. Fab. 139: Postquam Opis louem ex Saturno peperit; petit luno ut sibi eum concederet, quoniam Saturnus Orcum sub Tartara deiecerat et Neptunum sub undas, quod sciret tsi quis ex eo natus esset, se regno priuaret; qui cum Opem rogaret, ut esset, quod illa peperisset, illa lapidem inuolutum ostendit; eum Saturnus deuorauit; quod cum sensisset, coepit lovem quaerere per terras; luno autem louem in Cretensi insula detulit; at Amalthaea pueri nutrix eum in cunis in arbore suspendit, ut neque caelo neque terra neque mari inueniretur, et ne pueri uagitus exaudiretur; impuberes conuocauit eisque clipeola aenea et hastas dedit et iussit eos circum arborem euntes crepare; qui Graece Curetes sunt appellati; alii Corybantes dicunt, etc.

24 Grimal 1997, 398 ve 409-410. 
Giysiyle gizlenen bir kaya oturdu Saturnus'un gırtlağına, baba böyle aldatılmalıydı Parca'lar tarafından.

Uzun süre ses verir sarp Ida çınlamalarla, bebek güven içinde ağlasın diye.

Kimi yuvarlak kalkanlarına vurur değneklerle, kimi içi boş miğferlerine, şu işi yapmak Curet'lerin görevidir, diğeri Corybant'ların.

Gerçek gizlendi, eski uğraşıdan da taklitler kaldı; tanrıçanın eşlikçileri harekete geçirirler bronz çalgıları ve tiz ses veren derileri, zilleri şıngırdatırlar miğferler yerine, vururlar teflere kalkanlar yerine, Phrygia nağmeleri çalar flüt, eskiden çaldığı gibi ${ }^{25 \prime \prime}$. (Ovid. Fasti IV. 193-214).

Ovidius, tanrıçaya hizmet eden rahiplerin neden Phrygialı ve hadım olmaları gerektiğini, Attis söylencesiyle açıklar. Roller, tanıların Anası ile ilgili çeşitli tapım uygulamalarını açıklamak ve bu tapımın tuhaf yanlarına yani özellikle tanrıçanın Phrygialı rahiplerinin hadım oluşuna gerekçe göstermek için Hellen ve Romalı aydınlar tarafından Kybele ile Attis söylencesine kutsal bir öyküymüş (hieros logos) gibi işlev kazandırıldı̆ını söyler. Bunun asıl amacının, aslında her ikisi de Phrygia tanrıları olan Kybele'yle Attis'in, antik Hellen ve Roma dünyasıyla tanıştırılması olduğunu savunur $^{26}$. Arkeolojik buluntulardan Ana tanrıça tapımının MÖ I. binyılın başından itibaren Phrygia'da varolduğu bilinmektedir. Bu tapım, MÖ VI. yüzyıldan itibaren Helen dünyasına, MÖ III. yüzyılda ise Roma dünyasına girmiştir. Bu tapımın, varlığını sürdürdüğü yüzyıllar boyunca değişikliğe uğradığı, Kybele ve Attis'e ilişkin birçok farklı rivayetin olmasından anlaşılmaktadır. Roller, Attis adının Phrygia'da toplumsal açıdan sık rastlanan özel bir ad olduğunu ama bu adın, dinsel bir çevrede Phrygia'yı yöneten sınıfın önemli bir üyesinin hatta Ana tanrıçanın başrahibinin unvanı olarak kullanıldığını açıklar ve bu noktada tanrıçanın rahiplerinden hadım olma yoluyla temiz kalacaklarını göstermelerinin beklenmiş olabileceğini ileri sürer ${ }^{27}$. Nitekim Ovidius, Attis'in, tanrıçanın rahibi olarak kendisini kabul etmesi için ona ömür boyunca bakir kalma sözü verdiğini ve sözünden dönerse cezasını ölümle -yani kendisini hadım edip, erkekliğini öldürerek- ödeyeceğini şöyle ifade eder:

Bunu kendisine saklamak istedi tanrıça, tapınaklarını korumasını ve şöyle söyledi "yerine getir her zaman bakir kalmanın gereğini".

Beriki buyrukları yerine getireceğine yemin etti ve 'yalan söylersem, yeminimi bozduğum o aşk, benim sonum olsun' dedi. (Ovid. Fasti IV. 225-228).

Roller (1999, 250), Ana Tanrıça'nın Phrygialı rahiplerinin Attis'e öykünerek kendilerini hadım etmediklerini, aksine rahiplerin hadım olmasının Anadolu'da eski bir gelenek olduğunu söyler ve Kybele-Attis söylencesinin, bu geleneği açıklamak için uydurulduğunu savunur. Buna karşın Ovidius'un, Magna Mater'in rahiplerinin hadım olmaları gerektiğini aynı söylenceyle açıklamasının nedeni, Megalesia Festivali'nde yapılan ama Roma halkına ürkütücü görünen hadım etme törenine, kanımca mantıklı bir yanıt verme çabasından başka bir şey değildir. Romalılar erkeklerin kendilerini hadım etmelerinin gerçekten çılgınlık olduğunu düşünmüş olmalılar ki, insanları deliliğe sürüklediği için tanrıçaya Cybebe Mater adını vermişlerdir ${ }^{28}$.

25 Coşkun-Abuagla 2016, 183.

26 Roller 1999, 231.

27 Roller 1999, 238-239.

28 Fest. DSV. III, "Cybebe Mater," 51: Cybebe Mater, quam dicebant Magnam, ita appellabatur, quod ageret homines in furorem, quod Graeci kúbnbov dicunt. 
"Nereden geldi" dedim "rahiplerinin maslahatlarını kesme dürtüsü?" Ben susar susmaz, Pieris konuşmaya başladı: "Yüzü güzel mi güzel, Phrygia'lı bir çocuk olan Attis, kule taşıyan tanrıçayı bağladı kendisine saf aşkıyla. Bunu kendisine saklamak istedi tanrıça, tapınaklarını korumasını ve şöyle söyledi "yerine getir her zaman bakir kalmanın gereğini". Beriki buyrukları yerine getireceğine yemin etti ve 'yalan söylersem, yeminimi bozduğum o aşk, benim sonum olsun' dedi. Heyhat, bozar yeminini ve nympha Sagaritis'in içinde vazgeçer kalmaktan öncesinde kaldığı şeyi. Çok ağır olur cezaları tanrıçanın öfkesi yüzünden. Biçer naias'ı tanrıça, ağaçta yaralar açtıktan sonra, ölür o, çünkü ağaçtı naias'ın kaderi. Öbürü çıldırır ve yatak odasının tavanının çöktüğünü sanıp, kaçar ve koşa koşa Dindymus Dağı'nın zirvesine ulaşır. Kimizaman 'ortadan kaldır yanarcaları' kimi zaman 'yok et kırbaçları' diye haykırır; sık sık yemin eder Palaestina'lı tanrıçaların yanı başında olduğuna.

Hatta parçaladı bedenini keskin bir kayayla bulandı uzun saçları toza toprağa, bağırdı avaz avaz 'hakettim bunu' diye 'ödüyorum hakettiğim bedeli kanımla'. 'Ah! Yok olsunlar bana zarar vermiş parçalar! Ah! Yok olsunlar' deyip duruyordu hâlâ, kasığının yükünü kesip attığında ve kalmaz artık onda hiçbir erkeklik belirtisi işte o anda. Bu çılgınlık örnek oluşturur ve tanrıçanın efemine hizmetkârları keserler değersiz maslahatlarını, savura savura saçlarını" ${ }^{29}$.

(Ovid. Fasti IV. 221-244).

Festival günü praetor'lar tarafından tanrıçanın onuruna henüz çiftleşmemiş bir düve kurban edilirdi. Hem tanrıçanın yontusu hem de terracotta arabası Phrygialı bir rahip tarafından Almo Nehri'nin sularında yıkanırdı.

Önce çelenklerle süslediler gemiyi ve kurban ettiler lekesiz bir düveyi işten ve çiftleşmeden bihaber. Bir yer vardır Almo'nun Tiber'e doludizgin aktığı ve daha küçük olanın büyük nehirde adını kaybettiği yerde: Orada mor elbisesiyle kır saçlı bir rahip, Almo'nun sularıly tanrıçayı ve onun kutsal şeylerini yıkadı. Ulurlar eşlikçileri, çıldırmışçasına üflenir flüt ve boğa derisinden köseleleri döver efemine ellerï ${ }^{30}$. (Ovid. Fasti IV. 335-342).

Tanrıçanın efemine rahipleri, Galya toprağıyla hiç ilgileri olmadığı halde Gallus (Galyalı) sıfatıyla adlandırılırlar. Ovidius bunun sözcük kökeninin Phrygia'daki Kybele Dağı'yla onun yanında bir dağ ve kasaba olan Celaenae arasında akan Gallus Irmağı'yla ilişkili olduğunu söyler.

"O halde neden kendilerini hadım edenleri Gallus diye adlandırıyoruz,

Gallia toprağı Phrygia'dan o kadar uzakken?"

'Yeşil Cybele ile yüksek Celaenae arasında' dedi

'deli dolu suyuyla bir ırmak akar Gallus adında.

29 Coşkun-Abuagla 2016, 184-186.

30 Coşkun-Abuagla 2016, 190-191. 
Delirir ondan içen: Uzak dursun buradan, aklı başında kalmak isteyen: Delirir ondan içen ${ }^{31}$ ' (Ovid. Fasti IV. 361-366).

Romalılar, Magna Mater'in rahipleri olan Gallus'ların erkeklik gücünden yoksun bir efemine, oğlan çocuğu hatta bir kadın gibi olduklarını düşünmüşlerdir². Roller (1999, 310), Gallus'ların kadınsı görünümleri ve giysileri hakkında yapılan yorumlardan erkeklerin bunu onayladıklarını hatta böyle bir görüntünün erkeklerde heyecan uyandırdığını söyler. Lucretius, Megalesia Festivali'nde Gallus'lar tarafından yapılan gösteriler eşliğinde davullara, teflere vurulduğunu, zillerin şıngırdadığını, flütlerin, kavalların çalındığını ve tüm bunların insanlara heyecan verdiğini anlatır ${ }^{33}$. Ovidius da onların gösterilerini şöyle betimler:

Resmî geçit yapacak hadımlar ve içi boş teflere vuracaklar ve şıngırdayacak ziller, zillerin zillere vurulmasıly; taşınacak eşlikçilerinin efemine omuzlarında oturan tanrıça, kentin orta yollarında uluna uluna ${ }^{34}$. (Ovid. Fasti IV. 183-186).

Yasalar ve Senatus kararı gereği Romalı bir yurttaşın festivale özgü giysiler kuşanıp, flütçüler eşliğinde para toplaması yasakken tapım harcamalarının karşılanması için tanrıçanın hizmetindeki Phrygialı rahiplerin festival günlerinde bağış olarak para toplamasına hoşgörü gösterilirdi ${ }^{35}$. Halicarnassuslu Dionysius da bu efemine rahiplerin flütçüler eşliğinde ve rengârenk giysiler içinde kenti dolaşarak para topladıklarını aktarır.

"Söyle" dedim "tanrıça neden para istiyor küçük bir bağış olarak". 'Halk para topladı, Metellus'un tanrıçanın tapınağını yaptırdığı' dedi, 'işte o zamandan kaldı bağış verme âdeti ${ }^{36,}$.

(Ovid. Fasti IV. 350-353)

Festival günü tanrıçaya sarımsak, maydanoz, sedef otu, kişniş, soğan, peynir, zeytinyağı ve sirkeyle karıştırılan ve moretum olarak adlandırılan bir salata sunulurdu.

"Ayıp değil mi" dedim "yeşilliklerle yapılan sade bir salata koymak Ana Tanrıça'nın masalarına, yoksa başka bir neden mi var bunun altında?"

'Anlatıır eskilerin su katılmamış süt kullandıkları ve toprağın kendi gönlünce verdiği bitkileri' dedi.

'Beyaz peynir karıștırılır havanda dövülen yeşillikle, kadim tanrıça kadim yiyecekleri tanısın diye ${ }^{37}$. (Ovid. Fasti IV. 367-372).

31 Coşkun-Abuagla 2016, 192.

32 Catull. 63: ego mulier, ego adulescens, ego ephebus, ego puer, | ego gymnasi fui flos, ego eram decus olei.

33 Lucr. II. 614-623: Gallos attribuunt, quia, numen qui violarint| Matris et ingrati genitoribus inventi sint, | significare volunt indignos esse putandos, | vivam progeniem qui in oras luminis edant.| tympana tenta tonant palmis et cymbala circum | concava, raucisonoque minantur cornua cantu, | et Phrygio stimulat numero cava tibia mentis, | telaque praeportant, violenti signa furoris, | ingratos animos atque impia pectora volgi | conterrere metu quae possint numine divae.

35 Cic. DL. 2. 22: 'Praeter Idaeae Matris famulos eosque iustis diebus ne quis stipem cogito'. Dion. Hal. AR., II.

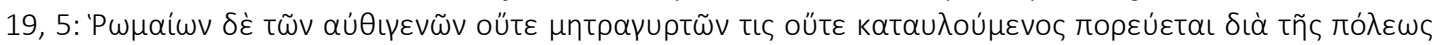

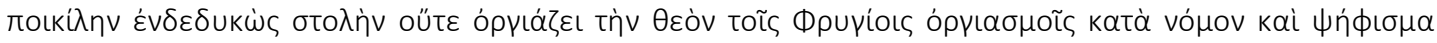

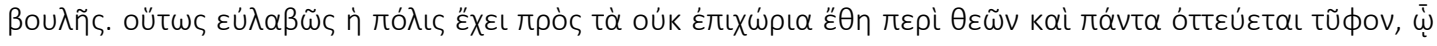




\section{BIBLIYOGRAFYA}

\section{Antik Kaynaklar}

Amm. Marc.

App. $H R$.

Arnob. AN.

Catull.

Cic. Brut.

Cic. $D H R$.

Cic. DL.

Dion. Hal. AR.

Fest. DSV.

Hyg. Fab.

Liv.

Lucr.

Ovid. Fasti

Plin. nat.

Varro Ling.

\section{Modern Literatür}

Coşkun-Abuagla 2013.

Coşkun-Abuagla, 2016.

Grimal 1997.

Roller 1999.
(= Ammianus Marcellinus, Historia Romana) Kullanılan Metin: J. C. Rolfe, Ammianus Marcellinus, Historia Romana. Cambridge 1935-1940.

(= Appianus, Historia Romana) Kullanılan Metin ve Çeviri: L. Mendelssohn, The Foreign Wars. Leipzig 1879.

(= Arnobius, Adversus Nationes) Kullanılan Metin ve Çeviri: G. F. Hildebrand, Maior sive Arnobius Afer, Adversus Nationes, Libri VII. n.d 1844.

(= Gaius Valerius Catullus, Carmina) Kullanılan Metin ve Çeviri: R. A. B. Mynors, Catulli Carmina. Scriptorum Classicorum Bibliotheca Oxoniensis. Oxford 1958.

(= Marcus Tullius Cicero, Brutus) Kullanılan Metin: G. L. Hendrickson - H. M. Hubbell, Marcus Tullius Cicero, Brutus. Cambridge, 1939.

(= Marcus Tullius Cicero, De Haruspicium Responsis) Kullanılan Metin: A. Clark, Marcus Tullius Cicero, De Haruspicium Responsis. Oxford 1909.

(= Marcus Tullius Cicero, De Legibus) Kullanılan Metin: G. de Plinval, Marcus Tullius Cicero, De Legibus. Paris 1959.

(= Dionysius Halicarnasensis, Antiquitates Romanae) Kullanılan Metin: K. Jacoby, Antiquitates Romanae quae supersunt, I-IV. Leipzig 1885.

(= Sextus Pompeius Festus, De Verborum Significatione) Kullanılan Metin: Sextus Pompeius Festus, De Verborum Significatione quae supersunt cum Pauli epitome. n.d. 1833.

(= Hyginus, Fabulae) Kullanılan Metin: M. Schmidt, Hygini Fabulae. Libraria Mauciana 1872.

(= Titus Livius, Ab Urbe Condita) Kullanılan Metin: G. Weissenborn - H. J. Müller, Titus Livius, Ab Urbe Condita Libri, I-X. Leipzig 1898.

(= Lucretius, De Rerum Natura) Kullanılan Metin: W. E. Leonard - E. P. Dutton, Lucretius, De Rerum Natura. Boston 1916.

(= Publius Ovidius Naso, Fasti) Kullanılan Metin: J. A. A. Du Rivier, omnia opera quae extant VIII, Bibliotheca Classica Latina sive Collectio Auctorum Classicorum Latinorum. Paris 1874.

(Plinius, Naturalis Historiae) Kullanılan Metin ve Çeviri: J. Bostock - H. T. Riley, The Natural History, Pliny the Elder. Londra 1855.

(= Marcus Terentius Varro, De Lingua Latina) Kullanılan Metin: R. G. Kent, Marcus Terentius Varro, De Lingua Latina. Cambridge 1938.

A. Coşkun-Abuagla, "The Cult of Meter Theon in Pisidian Conana". Gephyra 10 (2013) 132-134.

A. Coşkun-Abuagla, Fasti (I-VI) Roma Takvimi ve Festivaller. Ed. D. Önder. İstanbul 2016.

P. Grimal, Mitoloji Sözlüğü. İstanbul 1997.

L. E. Roller, Ana Tanrıça'nın Izinde, Anadolu Kybele Kültü. Çev. B. Avunç. İstanbul 1999. 